\title{
Strategies for life in flow: tenacity, morphometry, and probability of dislodgment of two Mytilus species
}

\author{
Emily C. Bell*, John M. Gosline \\ Department of Zoology, University of British Columbia, Vancouver, British Columbia, Canada V6T 1Z4
}

\begin{abstract}
The attachment strength of sessile intertidal organisms is continuously challenged by the hydrodynamic forces generated by breaking waves. This study explores mechanisms by which the attachment strength, or tenacity, can vary for one of the dominant competitors for space in this environment, the marine mussel. Tenacity was measured for 2 co-existing mussel species, Mytilus californlanus and Mytilus trossulus, either solitary or within a bed (= bed mussels). The tenacity of $M$. californianus was higher than $M$. trossulus, due to increased byssal thread thickness, and the tenacity of solitary mussels was higher than bed mussels, due to the presence of more byssal threads per mussel. These tenacity measurements were coupled with modeled hydrodynamic forces to predict the probability of dislodgment due to wave action. For a given water velocity, the predicted probability of dislodgment of $M$. californianus was lower than that of $M$. trossulus because the latter produces relatively thinner threads (reducing tenacity) and a relatively more voluminous shell (increasing hydrodynamic loading). Compared to solitary mussels, bed mussels had a lower probability of dislodgment for a given water velocity (despite their lower tenacity) because they are subjected to relatively smaller hydrodynamic forces. These predictrons are consistent with field observations that mussels typically form dense aggregations and that $M$. trossulus rarely inhabits highly wave-exposed shores.
\end{abstract}

KEY WORDS: Aggregation · Attachment strength - Biomechanics · Byssal thread · Hydrodynamic force . Intertidal - Mussel - Wave exposure

\section{INTRODUCTION}

The survival of sessile intertidal organisms is in part dependent on their ability to withstand the hydrodynamic forces associated with wave action. In extreme wave-exposed habitats, breaking waves generate water velocities in excess of $15 \mathrm{~m} \mathrm{~s}^{-1}$ and accelerations of $400 \mathrm{~m} \mathrm{~s}^{-2}$ (Jones \& Demetropoulos 1968, Denny 1985, 1988, Denny et al. 1985, Bell \& Denny 1994, Gaylord 1997). Such water motion can in turn generate large hydrodynamic forces that can challenge the attachment strength of sessile organisms (e.g. Denny et al. 1985, Denny 1987, 1995, Carrington 1990, Gaylord et al. 1994, Gaylord 1997).

Mussels are one of the dominant competitors for space in this mechanically stressful rocky intertidal

\footnotetext{
- Present address: Department of Biological Sciences, University of Rhode Island, Kingston, Rhode Island 02881, USA E-mail: bell@uriacc.uri.edu
}

environment (e.g. Paine 1974, 1976, Suchanek 1978, Seed \& Suchanek 1992), and one key aspect of their success is their ability to maintain a secure attachment to the substrate. Attachment is achieved by means of a byssus, which is an extracellular, collagenous secretion of the foot. As originally described by Brown (1952), the byssus is composed of 3 distinct parts: (1) the root, which is embedded in the basal region of the foot and is ultimately linked to the byssus retractor muscles, (2) the stem, which extends ventrally from the root and supports each byssal thread, and (3) the byssal threads, which extend from the stem in many directions, each attaching to the substrate by means of an adhesive plaque.

Numerous studies have identified factors that influence the byssal attachment strength of mussels. Attachment strength, or tenacity, often differs between co-existing species that are in direct competition for space. For example, Mytilus californianus has a stronger attachment than $M$. edulis (Harger 1970, Witman \& 
Suchanek 1984). Note that $M$. edulis was likely $M$. galloprovinclalis in the former study, and $M$. trossulus in the latter (MacDonald \& Koehn 1988). The attachment strength of $M$. galloprovincialis is also stronger than $M$. edulis (Gardner \& Skibinski 1991, Willis \& Skibinski 1992). Within a species, attachment strength has also been shown to increase with proximity to the mussel bed margin (Witman \& Suchanek 1984) and increased wave exposure [both geographically (Witman \& Suchanek 1984), and seasonally (Price 1980, 1982)].

In each of the above studies, the mechanism(s) controlling the variability of byssal attachment strength is unclear. One purpose of this study is to identify the location of mechanical failure of mussel byssus in situ. If mechanical failure typically occurs at the stem or root (as opposed to the threads), then variation in the strength of the byssal threads themselves would have no bearing on mussel tenacity. If, however, byssal threads are typically the weak link in the attachment system, then there are 3 potential mechanisms by which tenacity can be increased: (1) increasing the number of threads, (2) increasing the thickness of the threads, and (3) increasing the strength of the thread material. The first 2 of these mechanisms involve increasing the cross-sectional area over which an applied load is distributed, while the third mechanism involves an alteration of byssal thread material properties.

There is considerable evidence from laboratory studies that byssal thread production is dependent on a number of environmental cues, such as flow, salinity, and temperature (Van Winkle 1970, Allen et al. 1976, Lee et al. 1990, Seed \& Suchanek 1992, Dolmer \& Svane 1994). Thread number therefore seems a likely mechanism for increased tenacity, but the number of threads comprising byssal attachments in situ have not been documented. Byssal thread thickness varies with species (Bell \& Gosline 1996), but its role as a potential mechanism for increased mussel tenacity has been unexplored. The material properties of byssal threads produced by different mussel species have been detailed by Bell \& Gosline (1996) and indicate that, in comparison to Mytilus trossulus, $M$. edulis, and $M$. galloprovincialis, the threads of $M$. californianus extend further before breaking. The more extensible threads of $M$. californianus consequently provide a mechanism by which overall attachment strength is increased by 8 to $17 \%$ relative to the other species. Thus while all 3 of the potential mechanisms for increasing mussel tenacity are viable, it is not clear which, if any, of these mechanisms are important in determining the attachment strength of mussels in the field.

The survival of a mussel in the wave-swept environment is not only dependent on its tenacity, but also on the magnitude of the hydrodynamic forces it encounters. Such hydrodynamic forces are largely deter- mined by the size of the mussel and the flow regime to which it is exposed (Denny et al. 1985, Denny 1988. 1995). The force breaking waves impose on solitary mussels, which is primarily the 'in-line' force of drag and acceleration (Gaylord et al. 1994), is not necessarily of similar magnitude to that on mussels in a bed, which is primarily a lift force directed perpendicular to the substrate (Denny 1987). The relationship of tenacity to the hydrodynamic forces generated in these different flow regimes ultimately determines the ability of a mussel to survive in the wave-swept environment.

This study measures the tenacity of 2 co-existing mussel species, Mytilus californianus and $M$. trossulus, of both solitary individuals and those within a bed (= bed mussels). At the same study site, tenacity differs between species, and between solitary and bed mussels. The mechanisms accounting for this variation in tenacity are explored. By coupling tenacity measurements with predicted hydrodynamic forces, the probability of dislodgment for a given flow is predicted to be higher for $M$. trossulus than $M$. californianus. These results are consistent with the observation that $M$. californianus is the dominant competitor for space in the rocky intertidal zone, while $M$. trossulus is a shorterlived fugitive species. Further, dislodgment is predicted to be higher for solitary mussels than bed mussels, suggesting that aggregative behavior is a means of increasing survivorship in the wave-swept environment.

\section{MATERIALS AND METHODS}

Mussel tenacity. Tenacity, or attachment strength, was measured for 2 mussel species, Mytilus californianus and Mytilus trossulus, on a moderately exposed granitic shore of Ross Islets in Barkley Sound. British Columbia, Canada $\left(48^{\circ} 50^{\prime} \mathrm{N}, 125^{\circ} 08^{\prime} \mathrm{W}\right.$ ) in May and June 1993. The study site supported a healthy population of both species and represents a 'common garden' in that both species were exposed to the same largescale abiotic factors. Most mussels were within a bed, but solitary individuals were not uncommon.

The method of Denny (1987) was used to measure mussel tenacity. A recording spring scale was implemented with a hook that was threaded through a small hole drilled through the posterior end of the shell. The scale was lifted normal to the substrate until dislodgment occurred (after 1 to $2 \mathrm{~s}$ ). This dislodgment force (in $\mathrm{N}$ ) was recorded, as were maximum shell length (anterior-posterior), height (dorsal-ventral), and width (lateral), all measured with vernier calipers $( \pm 1 \mathrm{~mm})$. Shell planform area $\left(A_{\mathrm{pl}}\right.$, in $\left.\mathrm{m}^{2}\right)$ was approximated as an ellipse with shell height and width as major and minor axes, respectively. Tenacity $\left(\mathrm{N} \mathrm{m}^{-2}\right)$ was calculated as the dislodgment force divided by $A_{\mathrm{pl}}$. Note that 
although tenacity has the units of strength $\left(\mathrm{N} \mathrm{m}^{-2}\right)$, it should not be interpreted as a material property (sensu Wainwright et al. 1976), but rather, as a sizeindependent attachment force. Furthermore, $A_{p l}$ was selected as a characteristic index of mussel size for the tenacity calculations and does not necessarily reflect the area over which wave forces are typically applied.

Sample size was 137 to 140 for each of 4 categories (2 species $\times 2$ positions): solitary Mytilus californianus, solitary $M$. trossulus, bed $M$. californianus, and bed $M$. trossulus. Individuals were selected haphazardly, and samples of bed mussels were spaced far enough apart $(-40 \mathrm{~cm})$ so that they were unaffected by previous tenacity measurements. The anterior-posterior axis was typically oriented parallel to the substrate for solitary mussels and perpendicular to the substrate for bed mussels.

For each dislodged individual, the number of threads in the byssus was approximated (to the nearest 10) and the location of failure was determined (i.e. root, byssal threads, and/or substrate) It proved difficult to discriminate between failure occurring in the plaque adhesive or the thin layer of substrate to which the plaque adhered. Thus substrate failure is defined in this study to encompass both of these locations of failure, as well as larger-scale substrate failures (i.e. when attached to loose pebbles, abandoned barnacle tests, shell fragments, etc.). Occasionally, failure location was a combination of threads and substrate. For each of the 4 tenacity categories, a Kruskal-Wallis test was performed to evaluate the effect of failure location on tenacity (SigmaStat, Jandel Sci., San Rafael, CA, USA). Data were subsequently pooled and 2-way ANOVAs were performed to evaluate the effects of species and position on tenacity and on byssal thread number.

Morphometry. Individuals of each species were collected from the study site in June 1993 and brought to the laboratory for morphometric analyses $(n=104$ and 76 for Mytilus californianus and $M$. trossulus, respectively). Individuals were selected to span the size range observed in each species' population and were not positioned deeply within the bed so that growth was constrained by a neighbor, but were otherwise selected haphazardly. Shell length, height, and width were measured with vernier calipers $( \pm 1 \mathrm{~mm})$. A byssal thread was haphazardly sampled and its diameter measured $( \pm 1 \mu \mathrm{m})$ at a characteristic region (in the distal region $-3 \mathrm{~mm}$ from the adhesive plaque) using an ocular micrometer. Mussel weight was determined by remov- ing tissue from the shell, oven drying at $100^{\circ} \mathrm{C}$ to constant weight $(\sim 3 \mathrm{~d})$, then weighing to the nearest $0.01 \mathrm{~g}$. Shell weight was determined in a similar fashion. The shell was then filled with modeling clay. sealed with a light coating of wax, and its volume determined according to Archimedes' principle.

Least-squares linear regressions were performed to establish various morphometric relationships for the 2 species. With the exception of shell dimension comparisons, data were log-transformed for linear regression analyses due to heteroscedasticity. Thus for the allometric model $y=a x^{b}, b$ is the slope for a linear regression on $\log$-transformed data, while $\log (a)$ is the elevation. The elevation was corrected for log-transformation bias according to Sprugel (1983). A t-test was performed to compare regression slopes between species for each morphometric relationship (Zar 1984). When slopes were not found to differ, a common slope was computed and a t-test was performed to compare regression elevations. Mytilus californianus spanned a larger range in size (i.e. shell length, mussel weight, etc.) than $M$. trossulus, thus regressions were performed on a subset of data where the 2 species overlapped in shell size (length $=1.5$ to $5.0 \mathrm{~cm}_{i} \mathrm{n}=48$ and 70 for $M$. californianus and $M$. trossulus, respectively).

Probability of dislodgment. Hydrodynamic forces on a solitary and bed mussel were modeled for each species to predict the probability of dislodgment due to wave action (Fig. 1). For a solitary mussel, it was

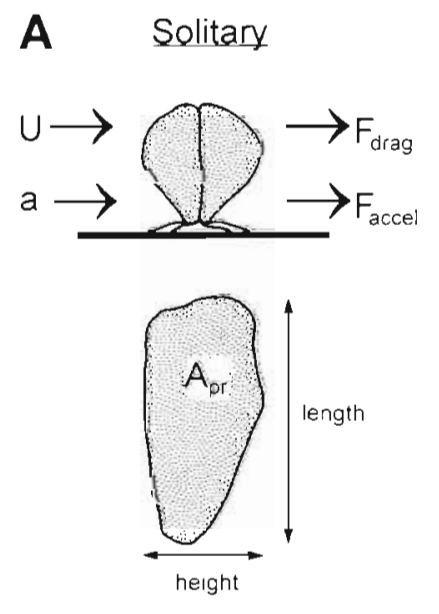

B

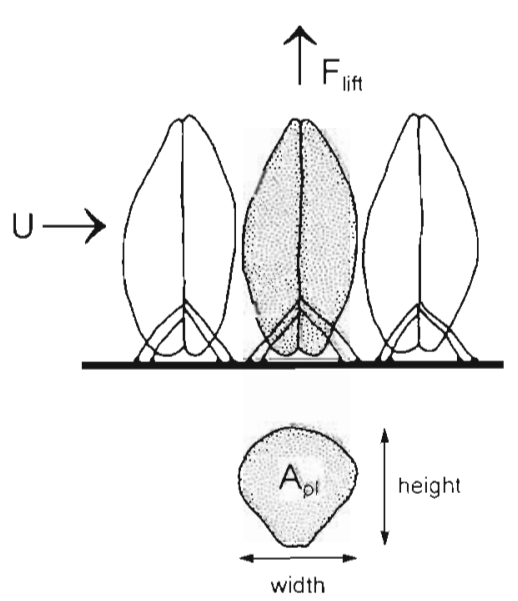

Fig. 1. Modeled hydrodynamic forces on a mussel. (A) A solitary mussel experiences forces in the direction of flow, due to both drag and accelerational forces $\left[F_{\text {drag }}\right.$ and $F_{\text {accel, }}$ respectively (Eqs. 1-3; see text for details)]. For a typical mussel oriented broad-side to flow, $A_{\mathrm{pr}}$ the area over which drag acts, is defined by shell length and shell height. $U$ : water velocity; $a$ : water acceleration. (B) A bed mussel experiences lift [ $F_{\text {lift }}$ force of lift (Eq. 4 ; see text for details)] perpendicular to the direction of flow. The area over which lift acts, $A_{p l}$. is defined by shell height and shell width for mussels in this characteristic orientation. Note that $A_{p r}$ is more than twice $A_{p l}$ for mussels in these orientations 
assumed that hydrodynamic forces act in the direction of flow and are therefore due to the sum of drag and accelerational forces ( $F_{\text {cirag }}$ and $F_{\text {sccel }}$, respectively; Gaylord et al. 1994):

$$
F_{\text {solitary }}=F_{\text {drag }}+F_{\text {accel }}
$$

Drag is dependent on the square of water velocity $\left(U\right.$, in $\left.\mathrm{m} \mathrm{s}^{-1}\right)$ and animal area $\left(A_{\mathrm{pr}}\right.$ as projected in the direction of flow, in $\mathrm{m}^{2}$ ), while accelerational force is dependent on water acceleration $\left(a_{1}\right.$ in $\mathrm{m} \mathrm{s}^{-2}$ ) and animal volume $\left(V\right.$, in $\left.\mathrm{m}^{3}\right)$ :

$$
\begin{gathered}
F_{\text {dray }}=\frac{1}{2} \rho U^{2} A_{\mathrm{pr}} C_{\mathrm{d}} \\
F_{\text {accel }}=\rho a V C_{\mathrm{tij}}
\end{gathered}
$$

$\rho$ is the density of sea water $\left(1024 \mathrm{~kg} \mathrm{~m}^{-3}\right)$ and $C_{d}$ and $C_{m}$ are the dimensionless coefficients of drag and inertia, respectively.

A solitary mussel was assumed to be oriented with its long axis parallel to the plane of the substrate, but perpendicular to the direction of flow (i.e. broadside, a worst-case scenario). $A_{\mathrm{pr}}$ was therefore calculated as the area of an ellipse with shell length and height as the major and minor axes, respectively. Shell height and width were calculated for a given shell length using the morphometric relationships established for each species, as described in the previous section. Shell volume was calculated from shell linear dimensions, again using morphometric relationships from this study. Water acceleration was assumed to be 20 times water velocity. Thus a moderate wave with a water velocity of $5 \mathrm{~m} \mathrm{~s}^{-1}$ had a corresponding water acceleration of $100 \mathrm{~m} \mathrm{~s}^{-2}$, while a more extreme wave, with a water velocity of $15 \mathrm{~m} \mathrm{~s}^{-1}$, had a corresponding water acceleration of $300 \mathrm{~m} \mathrm{~s}^{-2}$ This rough approximation is in general agreement with the few water acceleration measurements that have been made in the surf zone (Denny 1985, Denny et al. 1985, Gaylord 1997). $C_{d}$ and $C_{m}$ for a mussel in this orientation were assumed to be 0.8 and 2.0, respectively (based on measurements for Mytilus californianus reported by Denny et al. 1985).

A bed mussel was assumed to be subjected only to the hydrodynamic force of lift $\left(F_{h t}\right)$, acting perpendicular to the direction of flow (Denny 1987). Like drag, lift is dependent on the square of water velocity and animal area:

$$
F_{\text {bed }}=F_{\text {lift }}=\frac{1}{2} \rho U^{2} A_{p l} C_{1}
$$

where $C_{l}$ is the dimensionless coefficient of lift. The bed mussel was assumed to be oriented with its long axis perpendicular to the plane of the substrate. $A_{p l}$ was therefore calculated as the area of an ellipse with shell height and width as the major and minor axes, respectively. Shell height and width were determined for a given shell length using the morphometric relationships established in this study. $C_{1}$ for a mussel in this orientation was assumed to be 0.88 (Denny 1987).

For each of the 4 categories ( 2 species $\times 2$ positions), the variation in tenacity was described using a method similar to that of Gaines \& Denny (1993). Measurements were ranked in ascending order and the probability $p$ of having a tenacity less than a mussel of rankj was estimated as:

$$
p=j /(n+1)
$$

where $n$ is the total number of mussels sampled. A modified Weibull distribution was used to describe the probability $p$ that a given tenacity was less than $t^{\prime}$ :

$$
p=\exp -\left(\frac{\alpha-\beta t^{\prime}}{\alpha-\beta \varepsilon}\right)^{\frac{1}{\beta}}
$$

where $\alpha, \beta$, and $\varepsilon$ are model parameters. The Weibull model was iteratively fit to each data set with a maximum likelihood criterion for the goodness of fit using SYSTAT (SYSTAT Inc., Evanston, IL).

The probability of dislodgment was modeled for a given applied water velocity, shell length, and mussel category (e.g. a solitary Mytilus trossulus) as follows. Shell height and width were calculated from shell length using the morphometric relationships established in this study. The applied hydrodynamic force was then calculated, using the applicable equation described above (Eq. 1 or 4). This applied force was divided by shell planform area to normalize to size, following the same convention as for the tenacity measurements) to yield the scaled hydrodynamic force, which was inserted as $t^{\prime}$ in Eq. (6) to provide the probability of dislodgment.

\section{RESULTS}

\section{Mussel tenacity}

When mussels were experimentally dislodged from the substrate, 4 locations of failure were observed: root, thread, substrate, and a combination of thread and substrate. Root failure occurred in 12 to $23 \%$ of the samples, and failure at the stem was never observed. In 3 of the 4 tenacity categories, the substrate was the dominant location of attachment failure ( $60 \%$; Table 1$)$. Often a combination of events contributed to the substrate failures: adhesive plaques of byssal threads, loose pebbles, barnacle or mollusc shell, and weathered granite were all common points of weakest attachment. The exception to this generalization were bed Mytilus californianus, where the frequency of substrate failure was lower and thread failure was higher. 
Table 1. Mytilus californianus and M. trossulus. Location of attachment failure (\%) for mussels experimentally dislodged in the field. Sample size is 137 to 140 mussels for each column

\begin{tabular}{|c|c|c|c|c|}
\hline \multirow[t]{2}{*}{ Failure location } & \multicolumn{2}{|c|}{ M. californianus } & \multicolumn{2}{|c|}{ M. trossulus } \\
\hline & Solitary & Bed & Solitary & Bed \\
\hline Root & 23.4 & 15.7 & 17.1 & 11.7 \\
\hline Thread & 5.8 & 38.6 & 7.9 & 21.1 \\
\hline Thread + substrate & 10.2 & 12.1 & 11.4 & 3.7 \\
\hline Substrate & 60.6 & 33.6 & 63.6 & 63.5 \\
\hline
\end{tabular}

Tenacity was generally size-independent. For 3 of the 4 test categories, tenacity was not dependent on shell length $(p=0.25$ to 0.76 for a $t$-test on the slope of a linear regression, data not shown). The one exceptional category was bed Mytilus trossulus, where tenacity decreased slightly with increasing shell length $(p<0.05)$. However, shell length explained $<5 \%$ of the variation in tenacity in bed $M$. trossulus; thus it was assumed that tenacity (force per shell area) provided a reasonably size-independent measure of attachment strength and allowed for comparisons between categories.

Tenacity was not dependent on failure location for bed mussels of either species (Fig. 2). For solitary mussels of both species, however, failure location significantly affected tenacity ( 1 -way ANOVA, $\mathrm{p}<0.01)$, due to the higher tenacity of root failures (StudentNewman-Keuls multiple comparisons; $p=0.05$ ). The tenacity of root failures was higher in solitary than in bed mussels for both species ( $t$-tests, $p<0.001$ ).

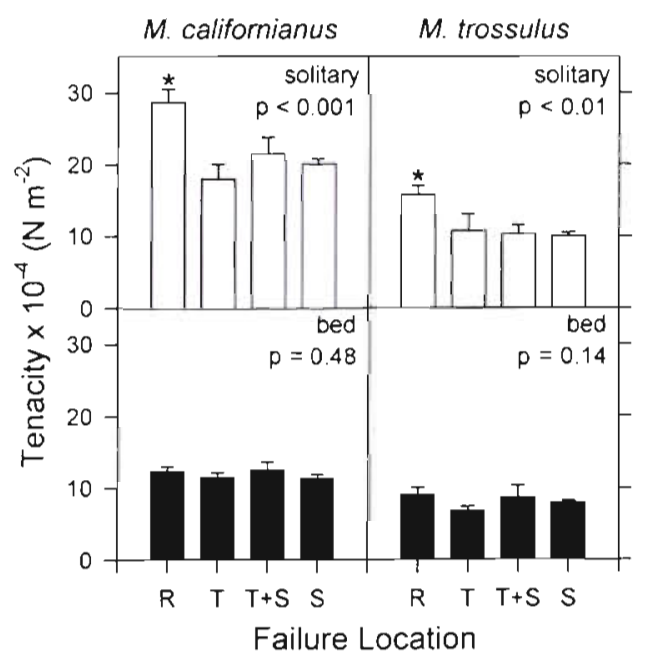

Fig. 2. Mytilus californianus and $M$. trossulus. Mean tenacity by failure location for solitary (open bars) and bed mussels (solid bars). Failure location categories: $\mathrm{R}=$ root, $\mathrm{T}=$ thread, $\mathrm{T}+\mathrm{S}=$ thread + substrate, and $\mathrm{S}=$ substrate. Error bars are standard errors. Probability $(p)$ is for a Kruskal-Wallis 1-way ANOVA (tenacity by failure location). ${ }^{*}$ Failure location with a significantly different mean tenacity $(p<0.05)$
When pooled for all failure locations, mussel tenacity was strongly dependent on both species and position (Fig. 3; data square-root transformed for statistical analysis). The tenacity of Mytilus trossulus was 33 to $50 \%$ lower than $M$. californianus $(p<0.001$ ), and the tenacity of bed mussels was 29 to $47 \%$ lower than solitary mussels $(p<0.001)$. The effects of species and position were interactive $(p<0.001)$, such that the increased tenacity of solitary mussels (compared to bed mussels) was more pronounced for $M$. californianus.

The number of threads produced by individual mussels was also significantly influenced by both species and position (Fig. 4; statistical analysis performed on ranked data). The byssus of Mytilus trossulus had more threads than $M$. californianus $(p<0.001)$, and solitary mussels produced more threads than bed mussels $(p<0.001)$. The interaction of species and position was not significant $(p=0.54)$. Note that reliable estimates of thread number were difficult to obtain for root failures because individual threads

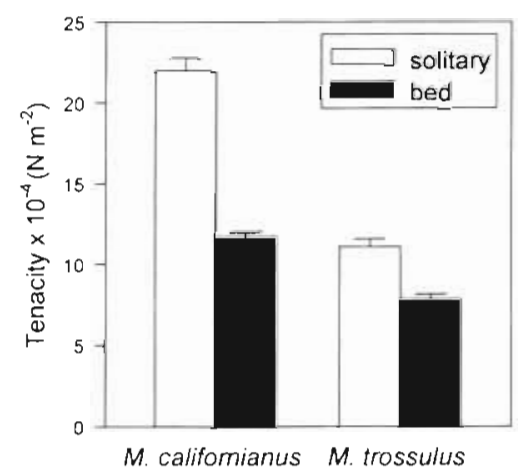

Fig. 3. Mytilus californianus and M. trossulus. Mean tenacity (all failure locations pooled) for solitary (open bars) and bed mussels (solid bars). Error bars are standard errors

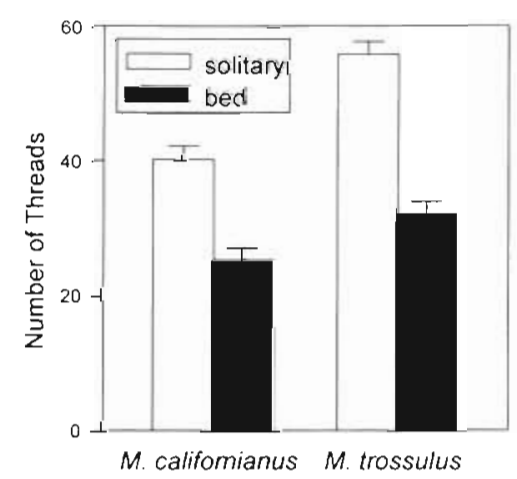

Fig. 4. Mytilus californianus and $M$. trossulus. Mean number of threads produced by solitary (open bars) and bed mussels (solid bars). All failure locations were pooled, except for root failures, where reliable measures were unobtainable. Error bars are standard errors 
Table 2. Mytilus calıfornianus and $M$. trossulus. Summary of linear regression analyses on morphometric relationships for 2 mussel species. Regressions were performed on similarly sized individuals (shell length $=1.5$ to $5.0 \mathrm{~cm}$ ) for the $2 \mathrm{species}$. A $t$-test was performed to compare regression slopes. In all cases, slopes were not found to differ between species; thus a common slope was computed and a $t$-test was perforned to compare regression elevations. $A_{p l}$ : shell planform area

\begin{tabular}{|c|c|c|c|c|c|c|}
\hline \multicolumn{2}{|c|}{ Regression variables } & \multicolumn{2}{|c|}{$\mathrm{p}(t$-test $)$} & \multirow{2}{*}{$\begin{array}{l}\text { Common } \\
\text { slope }\end{array}$} & \multicolumn{2}{|c|}{ Elevation } \\
\hline Independent & Dependent & Slope & Elevation & & M. californianus & M.trossulus \\
\hline Shell length $(\mathrm{cm})$ & Shell height $(\mathrm{cm})$ & 0.35 & $<0.001$ & 0.387 & 0.527 & 0.272 \\
\hline Shell length $(\mathrm{cm})$ & Shell width (cm) & $>0.5$ & 0.33 & 0.395 & 0.022 & 0.022 \\
\hline Shell length $\times$ height $\times$ width $\left(\mathrm{cm}^{3}\right)$ & Volume $\left(\mathrm{cm}^{3}\right)$ & 0.29 & -4 & 0.424 & $-{ }^{-\alpha}$ & $--^{a}$ \\
\hline $\log A_{\mathrm{p})}\left(\mathrm{cm}^{2}\right)$ & Log thread diameter $(\mu \mathrm{m})$ & 0.17 & $<0.001$ & 0.455 & 51.07 & 93.41 \\
\hline Log mussel wt (g) & Log thread diameter $(\mu \mathrm{m})$ & 0.19 & $<0.001$ & 0.298 & 2.247 & 2.092 \\
\hline Log mussel wt (g) & Log volume $\left(\mathrm{cm}^{3}\right)$ & $>0.5$ & $<0.001$ & 0.955 & 1.137 & 1.288 \\
\hline Log mussel wt (g) & Log shell wt (g) & $>0.5$ & $<0.005$ & 0.953 & 0.997 & 0.927 \\
\hline
\end{tabular}

were hard to locate and identify once separated from the animal. Root failures were therefore omitted from the 2 -way analysis

\section{Morphometry}

The morphometric relationships for the 2 species are summarized in Table 2. For shell dimensions, a linear regression on untransformed data provided a good fit $\left(r^{2}=0.93\right.$ to 0.99$)$ and model slopes did not differ significantly between species ( $p>0.35$ ). Model elevations differed significantly between the 2 species for height versus length $(p<0.001)$, but not for width versus length $(p=0.33)$. Thus, in comparison to Mytilus trossulus, the shell of $M$. californianus was on average the same width but $2.6 \mathrm{~mm}$ higher for a given shell length. The conversion of shell length $\times$ height $\times$ width to shell volume was the same for both species. Because these differences in shell morphology were fairly subtle, it was assumed that $C_{d}$ and $C_{m}$ were identical for the 2 species.

The remaining morphometric relationships required log-transformations for linear regression analysis due to heteroscedasticity (Table 2). The linear regression provided a good fit to the transformed data $\left(\mathrm{r}^{2}=0.90\right.$ to 0.98 , except for those involving thread diameter measurements, where $r^{2}=0.54$ to 0.59 ). For all of these log-transformed relationships, slopes did not differ significantly between species $(p>0.17)$, but elevations differed significantly $(p<0.005)$. Scaled to $A_{\mathrm{pl}}$, Mytilus trossulus byssal threads were $45 \%$ thinner than those of $M$. californianus (Fig 5). Scaled to mussel weight, $M$. trossulus byssal threads were $30 \%$ thinner and shell volume was $42 \%$ larger than $M$. californianus (Figs. $6 \&$ \& ). Despite the more voluminous shell, $M$. trossulus produced $15 \%$ less shell material (per mussel weight) than $M$. californianus (Table 2).

\section{Probability of dislodgment}

The predicted scaled hydrodynamic force for a solitary mussel was approximately twice that for a bed mussel (Fig. 8). These estimates did not differ between

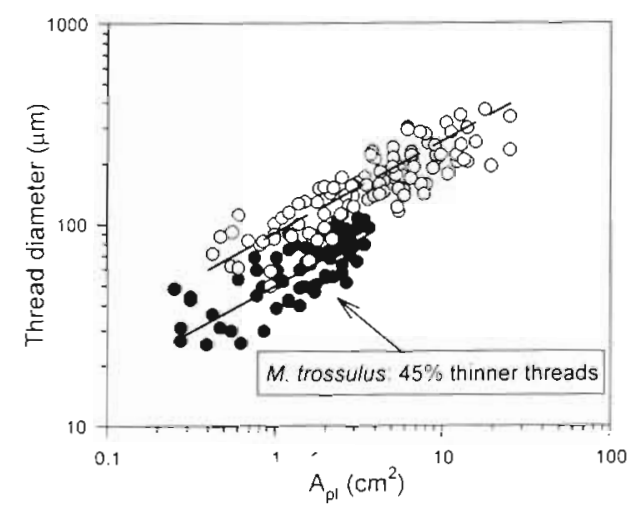

Fig. 5. Mytilus californianus $(0,---)$ ) and $M$. trossulus $(\bullet,-$. Morphometric scaling of byssal thread diameter with planform area $\left(A_{\mathrm{pl}}\right)$

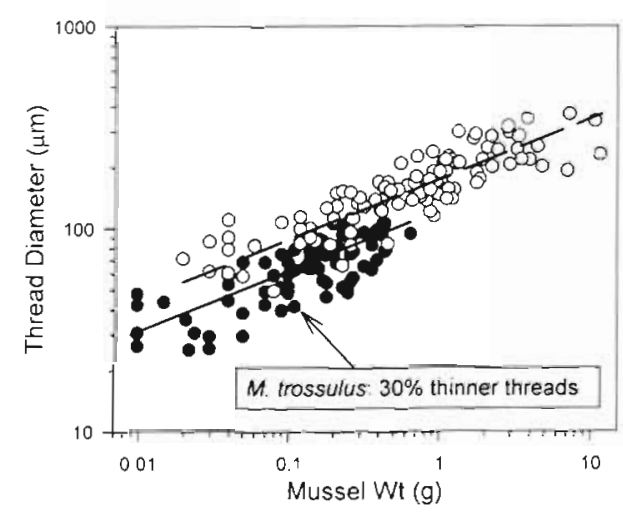

Fig. 6. Mytilus californianus $(0,-\ldots \rightarrow)$ and $M$. trossulus $(\bullet,-)$. Morphometric scaling of byssal thread diameter with mussel dry weight 


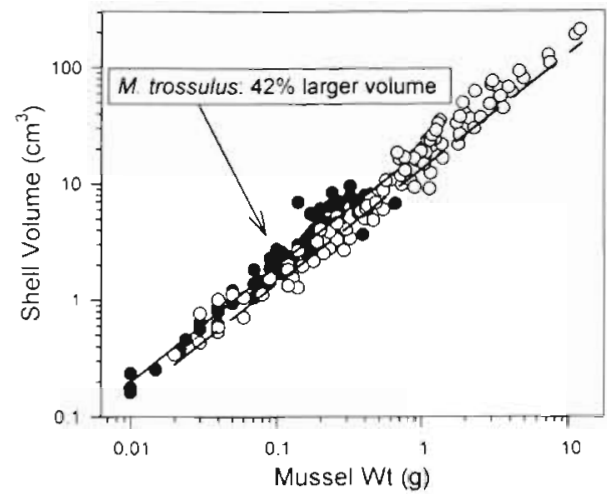

Fig. 7. Mytilus callformanus $(0,-\cdots-)$ and $M$. trossulus (_) Morphometric scaling of shell volume with mussel dry weight

species because of identical morphometric scaling of shell length and width. Scaled hydrodynamic force was size-independent for a bed mussel, and only modestly size-dependent for a solitary mussel (increasing shell length from 5 to $15 \mathrm{~cm}$ increased scaled hydrodynamic force by $\sim 11 \%$, data not shown). The scaled hydrodynamic force was 1 to $3 \times 10^{4} \mathrm{~N} \mathrm{~m}^{-2}$ for low water velocities $\left(<5 \mathrm{~m} \mathrm{~s}^{-1}\right)$, and exceeded 10 and $20 \times$ $10^{4} \mathrm{~N} \mathrm{~m}^{-2}$ for bed and solitary mussels, respectively, for higher water velocities (>15 $\mathrm{m} \mathrm{s}^{-1}$ ).

The Weibull model provided good estimates of cumulative probability versus mussel tenacity (Table 3 ; $r^{2}>0.99$ for all 4 categories). Combining these tenacity estimates with the above predictions of scaled hydrodynamic forces (Fig 9), the probability of mussel dislodgment for a given water velocity was influenced by both species and position. Dislodgment probability was always higher for Mytilus trossulus than $M$. californianus, and within species, was higher for solitary than bed mussels. For low water velocities $\left(<5 \mathrm{~m} \mathrm{~s}^{-1}\right)$, the probability of dislodgment was very low for all 4 cate-

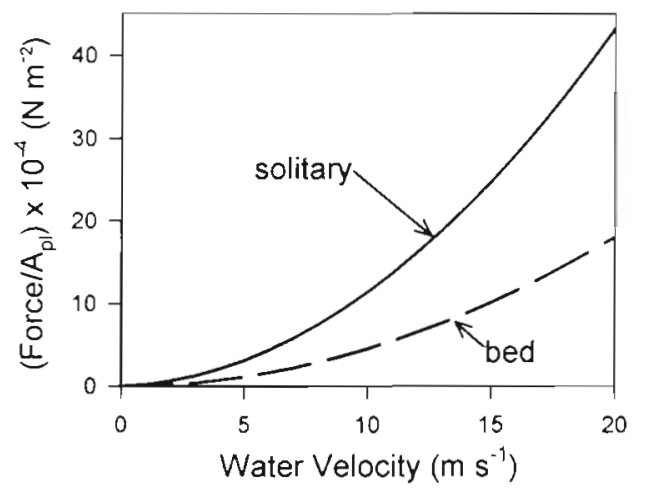

Fig. 8. Mytilus californianus and $M$. trossulus. Predicted scaled hydrodynamic force as a function of water velocity for either a solitary ( - ) or bed $(--\longrightarrow)$ mussel $5 \mathrm{~cm}$ in length. $A_{p l}$ : shell planform area
Table 3. Mytilus californianus and $M$. trossulus. Weibull mode] parameters (Eq. 6) for tenacity $\times 10^{4}\left(\mathrm{~N} \mathrm{~m}^{-2}\right)$ (either solitary or bed individuals)

\begin{tabular}{|lccccc|}
\hline & $\alpha$ & $\beta$ & $\varepsilon$ & $\mathrm{n}$ & $\mathrm{r}^{2}$ \\
\hline $\begin{array}{l}\text { M. californianus, } \\
\text { solitary }\end{array}$ & 9.381 & 0.070 & 17.978 & 137 & 0.991 \\
$\begin{array}{l}\text { M. californianus, } \\
\text { bed }\end{array}$ & 4.018 & 0.061 & 9.923 & 140 & 0.997 \\
$\begin{array}{l}\text { M. trossulus, } \\
\text { solitary }\end{array}$ & 4.761 & 0.012 & 8.430 & 140 & 0.996 \\
$\begin{array}{l}\text { M.trossulus, } \\
\text { bed }\end{array}$ & 3.923 & 0.138 & 6.468 & 137 & 0.994 \\
\hline
\end{tabular}

gories. For a $10 \mathrm{~m} \mathrm{~s}^{-1}$ water velocity, the probability of dislodgment was low for bed $M$. californianus (0.02), but high for solitary $M$. trossulus (0.65). In general, $M$. californianus can withstand water velocities that are 3 to $5 \mathrm{~m} \mathrm{~s}^{-1}$ higher than $M$. trossulus. Similarly, bed mussels can withstand water velocities that are 2 to $4 \mathrm{~m}$ $\mathrm{s}^{-1}$ higher than solitary ones. Model predictions were not substantially affected by mussel size (shell length 1 to $15 \mathrm{~cm}$, data not shown).

\section{DISCUSSION}

\section{Mussel tenacity}

The location of mechanical failure of experimentally dislodged mussels was most commonly the substrate. While many of these failures occurred in the adhesive plaque, it was not uncommon for failure to be due to friable rock, loose pebbles, or shell fragments. Substrate failure has also been noted as a common occurrence for experimentally dislodged acorn barnacles (Denny 1995). Thus the granitic shore in this study

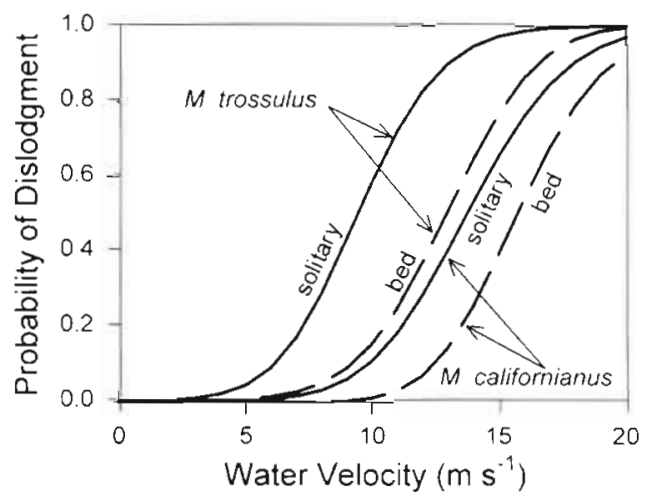

Fig 9. Mytilus californianus and $M$. trossulus. Predicted probability of dislodgment as a function of water velocity for solitary ( - ) and bed mussels (- $-1,5 \mathrm{~cm}$ in length 
does not necessarily provide a secure substrate for the attachment of sessile organisms; weakened surfaces abound, and substrate stability appears to be highly variable at small spatial scales. One advantage of a byssus composed of many threads radiating outward (as opposed to one thick thread) is an increased substrate area that is 'sampled' by the byssus, thereby increasing the likelihood that a stable piece of substrate is encountered. Whether or not instability is a common feature of other marine substrates (i.e. shale, sandstone) remains an open question.

Bed Mytilus californianus were exceptional in that substrate failures were less frequent while thread failures were more frequent. This was probably due to the fact that the mussel bed from which these samples were taken was many layers thick; thus the individuals sampled were attached to other mussel shells and not to primary substrate (data not shown). In contrast, $M$. trossulus beds were a monolayer, so that while some threads were attached to neighboring mussels, most threads were attached to primary granitic substrate. The decreased frequency of substrate failure for bed $M$. californianus, at the expense of increased thread failure, suggests that congener shell provides a more reliable site for attachment than the primary substrate. Increased attachment strength on mussel shell versus primary substrate has been proposed for other intertidal invertebrates as well (Lohse 1993).

Failure at the root was observed in 12 to $23 \%$ of the mussels experimentally dislodged from the substrate. While accurate measures of thread number were difficult to obtain for failures at this location, high thread numbers were often noted $(>100)$. The tenacity of root failures tended to be higher than the other failure locations. These observations suggest that the strength of the root/byssus gland junction is generally greater than the summed strengths of individual threads. Presumably, root failure occurs only in the event that many threads are present. In this manner, the strength of the root/byssus gland junction appears to set an upper limit to attachment strength in mussels. Note that for both species, solitary mussels had stronger junctions than bed ones, suggesting that the strength of this junction is under the active control of the mussel. Indeed, mussels have been observed to 'jettison' the byssus by releasing this junction under laboratory conditions (Brown 1952, authors' pers. obs.).

Mussel tenacity varied among test categories due to the influences of species and position. Specifically, solitary mussels were more securely attached than those within a bed, and the tenacity of Mytilus californianus was higher than that of $M$. trossulus. As long as the strength of the root is not exceeded (which occurred in only $\sim 20 \%$ of the samples), there are 3 mechanisms by which a mussel may increase its tenacity: (1) increasing thread number, (2) increasing thread thickness, and (3) increasing thread strength. Note that the first 2 mechanisms still apply in cases where substrate failures are common: the area of substrate that is sampled by a byssus increases with thread number and thread thickness [since thread thickness and adhesive plaque size are positively correlated (Bell unpubl. data)]. The third mechanism, increasing thread strength, would likely not apply because the strength of the substrate itself determines attachment strength.

The first of these mechanisms, byssal thread number, accounts for much of the observed variation in tenacity in solitary versus bed mussels. For both species, the reduction in tenacity of bed mussels was mirrored by a similar reduction in thread number (Figs. $3 \& 4$ ). Thread number was also dependent upon species, with Mytilus trossulus producing more threads than $M$. californianus. However, this species-difference does not account for the observed variation in tenacity between species: despite a byssus with fewer threads, $M$. californianus had a stronger attachment than $M$. trossulus. Thus thread number is a likely mechanism by which position, but not species, can influence mussel tenacity.

Bell \& Gosline (1996) have detailed differences in the mechanical properties of the byssal threads of these 2 species, where the initially stiffer and ultimately more extensible threads of Mytilus californianus increase overall attachment strength by 8 to $17 \%$. However, this difference in material properties is too small to account for the difference in tenacity between species observed in this study (33 to 50\%). Further, thread strength is an unlikely mechanism to explain speciesdifferences, since failure most often occurred at the substrate. Instead, the primary mechanism involved is a morphometric difference in thread thickness between the 2 species: for a given $A_{\mathrm{pl}}$ (which is the conventional scaling term for tenacity in this study), $M$. trossulus threads are $45 \%$ thinner than those of $M$. californianus. This corresponds to a $70 \%$ reduction in individual thread cross-sectional area. $M$. trossulus does produce slightly more byssal threads, but not enough to overcome the large difference in thread cross-sectional area between the 2 species. The net result is a reduction in the total area over which a load is distributed and a concomitant reduction in tenacity for $M$. trossulus.

Overall, this study suggests that the primary mechanisms affecting mussel tenacity are (1) increased thread number and (2) increased thread thickness; the former accounts for the influence of position on tenacity, while the latter accounts for the influence of species. 


\section{Morphometry}

From the above discussion, one important morphometric difference between Mytilus trossulus and $M$. californianus is in the scaling of byssal thread diameter with shell planform area. When morphometric measurements are instead scaled to mussel dry weight, it can be seen that the difference in thread diameter versus $A_{\mathrm{pl}}$ is the result of 2 morphological differences between the 2 species: for a given mussel weight, $M$. trossulus produced thinner byssal threads and a more voluminous sheli than $M$. californianus. Note that there was a significant, but relatively small, difference in the amount of shell produced for a given mussel weight ( $M$. trossulus produced $15 \%$ less shell mass than $M$. californianus). Thus these 2 species appear to allocate similar proportions of their total energy budget to shell production. Where these 2 species differ, however, is in the size of the shell that they produce for a given mussel weight: shells of $M$. trossulus were $42 \%$ more voluminous than $M$. californianus. The hydrodynamic consequences of these morphometric differences will be discussed below. Note that $M$. trossulus shells were also relatively thinner (interior-exterior), since slightly less shell material was distributed over a larger shell size, and may therefore be more susceptible to drilling by gastropods or crushing by crabs or other mussels (Harger 1971, Palmer 1992).

\section{Probability of dislodgment}

Scaled to mussel dry weight, Mytilus trossulus produces relatively thinner byssal threads (reducing its tenacity) and a larger shell (increasing its hydrodynamic loading). The combination of these morphometric differences has the important consequence of increasing the probability of dislodgment of $M$. trossulus relative to $M$. californianus. The magnitude of this difference is substantial: relative to $M$. californianus, equivalent probabilities of dislodgment for $M$. trossulus occur at water velocities that are 3 to $5 \mathrm{~m} \mathrm{~s}^{-1}$ lower. Particularly for solitary mussels, the survival of $M$. trossulus is predicted to be very low on waveexposed coasts, where water velocities commonly exceed $10 \mathrm{~m} \mathrm{~s}^{-1}$

The predicted probabilities of dislodgment are essentially size-independent because of the relatively small contribution of accelerational forces to the total in-line force $\left(<30 \%\right.$ for water velocities $\left.>8 \mathrm{~m} \mathrm{~s}^{-1}\right)$ over the size range of mussels commonly observed. Because Mytilus californianus has a lower probability of dislodgment, it is more likely to live longer and grow larger than $M$. trossulus. This hydrodynamically based prediction is consistent with the observation that $M$. californianus is a larger, longer-lived, superior competitor for space than the smaller, faster-growing, fugitive $M$. trossulus (Suchanek 1981, as $M$. edulis). In addition to small size and the lack of predatordeterring mechanisms (Suchanek 1981), the reduced investment in attachment strength of $M$. trossulus relative to its hydrodynamic loading can be considered yet another means by which this species channels energy into rapid growth and reproductive effort.

In comparison to solitary mussels, bed mussels of both species had lower probabilities of dislodgment despite a lower relative tenacity. This is due to the larger magnitude of the scaled hydrodynamic force for solitary versus bed mussels. Because of the small contribution of accelerational forces, the difference between solitary and bed mussels is that the former experiences primarily drag, while the latter experiences primarily lift. The equations defining these forces are essentially identical $\left(C_{d}\right.$ and $C_{l}$ are comparable), except for differences in the area over which a force acts. The relevant area for a solitary mussel, $A_{p r}$, is 2.5 -fold higher than that for a bed mussel, $A_{\mathrm{pl}}$. Consequently, a solitary mussel experiences over twice the hydrodynamic force of a bed mussel for a given velocity. For both species, however, the increased tenacity of a solitary mussel is not sufficient to counteract this higher hydrodynamic loading and solitary mussels consequently have higher probabilities of dislodgment than bed mussels for a given water velocity. Note that $A_{\mathrm{pr}} / A_{\mathrm{pl}}$ equals shell length/width and is identical for the 2 species in this commongarden study (Table 2). However, shell length/width has been shown to be highly plastic in Mytilus edulis (due to a number of factors, Seed 1968), which could have a modest effect on the magnitude of the flow forces a mussel encounters. Morphometric differences between bed and solitary mussels were not readily apparent for the species in this study (authors' pers. obs.).

Because of reduced hydrodynamic loading, bed mussels have less stringent requirements for attachment strength. The metabolic cost of byssus production can be substantial, forming up to $8 \%$ of a mussel's total energy expenditure (Hawkins \& Bayne 1985). Mussels are typically found in beds, and such aggregative behavior may therefore be a means by which energy may be channeled away from the formation of bysus and into growth and reproduction. However, this potential advantage must be weighed with numerous other affects of aggregation, such as reduced feeding efficiency and growth (e.g. Okamura 1986, Frechette et al. 1989, O'Riordan et al. 1993, Butman et al. 1994), attraction of predators (Robles et al. 1995), increased juvenile survival in protected interstices (e.g. Bertness \& Grosholz 1985), and increased fertilization success (e.g. Denny \& Shibata 1989, Levitan 1991). 
Hydrodynamic forces were modeled for a solitary mussel oriented broadside, with its long axis perpendicular to the direction of flow. If a mussel were instead oriented with its long axis parallel to flow (i.e. end-on), drag would be generated over a smaller $A_{p r}$ reducing hydrodynamic loading and probability of dislodgment (Denny et al. 1985). Mussels have been observed to orient actively end-on to flow in the laboratory (Dolmer \& Svane 1994), but in the field this behavior can be beneficial only in microhabitats where flow direction is predictable, such as in surge channels. For the majority of the wave-swept rocky intertidal zone, complex topography renders even the most simple, orderly waves into chaotic flows once they break at the shore. Consequently, the direction of maximum flow is highly unpredictable (Denny 1985). Since it is the maximal forces that have the greatest influence on dislodgment, only the worstcase scenario of a broadside orientation was modeled for a solitary mussel. Note that lift acts perpendicular to flow and is more predictably oriented. By orienting their long axis normal to the substrate, bed mussels are predictably able to present a small area over which hydrodynamic forces are generated.

In this study, tenacity was measured by loading a mussel normal to the substrate. This is the same direction as lift and therefore provides an appropriate measure of tenacity for bed mussels, but not for solitary mussels, which are loaded parallel to the substrate. Bell \& Gosline (1996) have modeled the attachment strength of a byssus with uniformly distributed, radially arranged threads and predict that the tenacity measured parallel to the substrate is 53 to $57 \%$ of that measured normal to substrate. This prediction remains to be verified with field measurements, but if true, such a correction of tenacity measurements for directionality would further increase the predicted probability of dislodgment for solitary mussels of both species.

For water velocities that are typical of waveexposed shores during winter storms $\left(>15 \mathrm{~m} \mathrm{~s}^{-1}\right)$, the model predictions of dislodgment probability are quite high, ranging 40 to $100 \%$ for the 4 categories. However, this model was based on tenacity measurements made in the summer, when heavy wave action is rare, and on a moderately exposed shore. Mussel tenacity has been shown to vary seasonally, presumably in response to increased wave action (Price 1980, 1982). Similarly, the tenacity of Mytilus trossulus is higher in wave-exposed habitats than in sheltered habitats (Witman \& Suchanek 1984, as $M$. edulis). It is not clear how such increased tenacity is achieved, but one likely mechanism is through increased thread number, in the same manner in which solitary mussels, which are exposed to higher hydrodynamic loading, increase their tenacity relative to bed mussels.
Inasmuch as mussels are able to sense increased wave action (either seasonally or geographically) and respond with increased tenacity, the probability of dislodgment would shift to lower values than presently predicted.

The model presented in this study focuses on the extremes of mussel position, either solitary or within a densely packed bed. Mussels on the fringe of a bed are likely intermediately exposed to higher, more solitarylike, hydrodynamic forces than those well within a bed. Indeed, mussel tenacity is higher at the edge of a bed than within a bed (Witman \& Suchanek 1984), perhaps in response to increased hydrodynamic loading. It is unknown whether this increased tenacity keeps pace with the increased loading and how the probability of dislodgment is affected. The cost to a mussel on the fringe, however, is an increased allocation of energy to attachment strength.

Despite the low probability of dislodgment, bed mussels are occasionally dislodged, either due to lift alone or to the increased drag-induced loading caused by algal epibionts (Paine \& Levin 1981, Witman \& Suchanek 1984, Denny 1987, 1995, Witman 1987). The result is the formation of a small gap in the bed that is outlined by weakly attached, formerly 'bed' mussels that (depending on the size of the gap) are suddenly exposed to higher, more solitary-like hydrodynamic forces. Unless these mussels can rapidly increase their tenacity before the arrival of additional large waves, they too will be dislodged and, as proposed by Denny (1987), a chain-reaction of dislodgment can occur. In this manner, a considerable amount of patch formation can result with the initial removal of an individual mussel from a bed.

Overall, this study demonstrates 2 strategies for mussels to increase survivorship in the surf zone. Increased byssal thread thickness and reduced shell size increase tenacity and decrease hydrodynamic loading, respectively, and have the net effect of decreasing the risk of dislodgment by wave action. In addition, mussels can aggregate into a dense bed, which has the effect of reducing hydrodynamic loading and provides less stringent requirements for attachment strength. Mytilus californianus has adopted both of these strategies, which may contribute to its competitive dominance on the most extreme of waveexposed shores.

Acknowledgements. We thank the faculty and staff of Bamfield Marine Station for providing excellent facilities for portions of this study. M. Kasapi, E. Luiker, G. David, K. Miller, R. Saunders, and M. Bell assisted in the fjeld work. $J$. Geller verified species identification and F. Shaughnessy provided statistical expertise. This study was supported by a Killam Postdoctoral Fellowship, an Elose Gerry Fellowship of the SDE/Graduate Women in Science, and a Bamfield Marine 
Station Research award to E.C.B. and by NSERC grant \#86934 to J.M.G.

\section{LITERATURE CITED}

Allen JA, Cook M, Jackson DJ, Preston S, Worth EM (1976) Observations on the rate of production and mechanical properties of the byssus threads of Mytilus edulis $\mathrm{L}$. J Molluscan Stud 42:279-289

Bell EC, Denny MW (1994) Quantifying 'wave exposure' a simple device for recording maximum velocity and results of its use at several field sites. J Exp Mar Biol Ecol 181: 9-29

Bell EC, Gosline JM (1996) Mechanical design of mussel byssus: material yield enhances attachment strength. J Exp Biol 199:1005-1017

Bertness MD, Grosholz E (1985) Population dynamics of the nbbed mussel, Geukensia demissa: the costs and benefits of an aggregated distribution. Oecologia 67: 192-204

Brown CH (1952) Some structural proteins of Mytilus edulis L. Q J Microsc Sci 93:487-502

Butman CA, Frechette M, Geyer WR (1994) Flume experiments on food supply to the blue mussel Mytilus edulis L. as a function of boundary layer flow. Limnol Oceanogr 39:1755- 1768

Carrington E (1990) Drag and dislodgement of an intertidal macroalga: consequences of morphological variation in Mastrocarpus papillatus Kutzing. J Exp Mar Biol Ecol 139: $185-200$

Denny MW (1985) Wave forces on intertidal organisms: a case study. Limnol Oceanogr 30:1171-1187

Denny MW (1987) Lift as a mechanism of patch initiation in mussel beds. J Exp Mar Biol Ecol 113:231-245

Denny MW (1988) Biology and the mechanics of the waveswept environment. Princeton University Press, Princeton, NJ

Denny MW (1995) Predicting physical disturbance: mechanistic approaches to the study of survivorship on wave-swept shores. Ecol Monogr 65:371-418

Denny MW, Daniel TL, Koehl MAR (1985) Mechanical limits to size in wave-swept organisms. Ecol Monogr 55:69-102

Denny MW, Shibata MF (1989) Consequences of surf-zone turbulence for settlement and external fertilization. Am Nat 134:859-889

Dolmer P, Svane I (1994) Attachment and orientation of Mytilus edulis L. in flowing water. Ophelia 40:63-74

Frechette M. Butman CA, Gever WR (1989) The importance of boundary-layer flow in supplying phytoplankton to the benthic suspension feeder, Mytilus edulis L. Limnol Oceanogr 34:19-36

Gaines SD, Denny MW (1993) The largest, smallest, highest, lowest, longest, and shortest: extremes in ecology. Ecology $74: 1677-1692$

Gardner JPA, Skibinski DOF (1991) Biological and physical factors influencing genotype-dependent mortality in hybrid mussel populations. Mar Ecol Prog Ser 71:235-243

Gaylord B (1997) Consequences of wave-induced water motion to nearshore macroalgae. PhD dissertation, Stanford University

Gaylord B, Blanchette CA, Denny MW (1994) Mechanical consequences of size in wave-swept algae. Ecol Monogr $64: 287-313$

Harger JRE (1970) The effect of wave impact on some aspects of the biology of sea mussels. Veliger 12:401-414

Harger JRE (1971) Competitive co-existence: maintenance of interacting associations of the sea mussels Mytilus edulis and Mytilus californianus. Veliger 14:387-410

Hawkins AJS, Bayne BL (1985) Seasonal variation in the relative utilization of carbon and nitrogen by the mussel Mytilus edulis: budgets, conversion efficiencies and maintenance requirements. Mar Ecol Prog Ser 25: $181-188$

Jones WE, Demetropoulos A (1968) Exposure to wave action: measurements of an important ecological parameter on rocky shores of Anglesey. J Exp Mar Biol Ecol 2:46-63

Lee CY, Lim SS, Owen MD (1990) The rate and strength of byssal reattachment by blue mussels (Mytilus edulis L.). Can J Zool 68:2005-2009

Levitan DR (1991) Influence of body size and population density on fertilization success and reproductive output in a free-spawning invertebrate. Biol Bull (Woods Hole) $181: 261-268$

Lohse DP (1993) Effects of substratum type on population dynamics. J Exp Mar Biol Ecol 173:133-154

McDonald JH, Koehn RK (1988) The mussels Mytilus galloprovincialis and Mytilus trossulus on the Pacific coast of North America. Mar Biol 99:111-118

Okamura B (1986) Group living and the effects of spatial position in aggregations of Mytilus edulis. Oecologia 69: $341-347$

O'Riordan CA, Monismith SG, Koseff JR (1993) A study of concentration boundary-layer formation over a bed of model bivalves. Limnol Oceanogr 38:1712-1729

Paine RT (1974) Intertidal community structure: experimental studies on the relationship between a dominant competitor and its principal predator. Oecologia 15:93-120

Paine RT (1976) Size limited predation: an observational and experimental approach with the Mytilus-Pisaster interaction. Ecology 57:858-873

Paine RT, Levin SA (1981) Intertudal landscapes: disturbance and the dynamics of pattern. Ecol Monogr 51:145-178

Palmer AR (1992) Calcification in marine molluscs: how costly is it? Proc Natl Acad Sci 89:1379-1382

Price HA (1980) Seasonal variation in the strength of byssal attachment of the common mussel Mytilus edulis L. J Mar Biol Assoc UK 60:1035-1037

Price HA (1982) An analysis of factors determining seasonal variation in the byssal attachment strength of Mytilus edulis. J Mar Biol Assoc UK 62:147-155

Robles C. Sherwood-Stephens R, Alvarado M (1995) Responses of a key intertidal predator to varying recruitment of its prey. Ecology 76:565-579

Seed R (1968) Factors influencing shell shape in the mussel Mytulus edulis. J Mar Biol Assoc UK 48:561-584

Seed R, Suchanek TH (1992) Population and commumity ecology of Mytilus. In: Gosling EG (ed) The mussel Mytilus: ecology, physiology, genetics and culture. Elsevier, New York, p $87-169$

Sprugel DG (1983) Correcting for bias in log-transformed allometric equations. Ecology 64:209-210

Suchanek TH (1978) The ecology of Mytilus edulis L. in exposed rocky intertidal communities. J Exp Mar Biol Ecol 31:105-120

Suchanek TH (1981) The role of disturbance in the evolution of life history strategies in the intertidal mussels Mytilus edulis and Mytilus californianus. Oecologia 50: $143-152$

Van Winkle W (1970) Effect of environmental factors on byssal thread formation. Mar Biol 7:143-148

Wainwright SA, Biggs WD, Currey JD, Gosline JM (1976) Mechanical design in organisms. Princeton University Press, Princeton, NJ 
Willis GL, Skibinski DO (1992) Variation in strength of attachment to the substrate explains differential mortality in hybrid mussel (Mytilus galloprovincialis and Mytilus edulis) populations. Mar Biol 112:403-408

Witman JD (1987) Subtidal coexistence: storms, graxing, mutualism. and the zonation of kelps and mussels. Ecol

Editorial responsibility: Otto Kinne (Editor),

Oldendorf/Luhe, Germany
Monogr 57:167-187

Witman JD. Suchanek TH (1984) Mussels in flow: drag and dislodgement by epizoans. Mar Ecol Prog Ser 16: $259-268$

Zar J (1984) Brostatistical analysis. Prentice-Hall, Englewood Cliffs, NJ

Submitted: June 24, 1996 Accepted: July 16, 1997 Proofs received from author(s): November 5. 1997 